\title{
De la colectividad a la comunidad. Reflexiones acerca del derecho de propiedad en Llanchu, Perú
}

\author{
Ingrid Hall ${ }^{1}$
}

Recibido: 9 de enero de 2017 / Aceptado: 25 de marzo de 2017

Resumen. La comunidad es una institución clave en la organización social de la población rural del Perú, esencialmente andina; se estima que la gestión común de la tierra es su rasgo fundamental. La reforma agraria de 1969 abrió en este sentido una etapa muy importante al atribuir a nombre de la comunidad, legalmente reconocida, un título de propiedad colectivo de sus tierras. A través de datos etnográficos analizaremos en este artículo el caso específico de la comunidad campesina de Llanchu (Calca, Cusco). Mostraremos cómo la obtención del estatus de comunidad campesina y de un título de propiedad fueron fundamental para la formación y la estructuración de una comunidad en el sentido sociológico del término. Nos interesamos más precisamente en el pluralismo jurídico y en la dimensión generativa del derecho, analizando la manera como medidas externas impulsaron en la comunidad cambios internos al nivel local.

Palabras claves: Comunidades campesinas; propiedad; comunes; usufructo; pluralismo jurídico; Perú.

\section{[en] From collectivity to community. Reflections on the property rights in Llanchu, Peru}

Abstract. The community is a very important institution in the rural areas of Peru, especially in the Andes. It is admitted that the common management of land is one of its main feature. The agrarian reform of 1969 represents a very important event in that perspective as communities recognized by the state received a collective property title for their land. Through ethnographical data's from the community of Llanchu (Calca, Cusco), we will show how obtaining the status of peasant community and the title have been fundamental elements in the process of formation and structuration of the community in sociological terms. We will focus on the legal pluralism and its generative dimension to show how external decisions had internal consequences at a local level.

Keywords: Peasant communities; property; commons; usufruct; legal pluralism; Peru.

Sumario. Introducción. 1. Precisiones teóricas, conceptuales e históricas. 2. La comunidad campesina de Llanchu, formación y organización agraria. 2.1. La obtención de la propiedad de la tierra, un objetivo primordial. 2.2. De la propiedad colectiva de las tierras a su uso familiar. 3. El control social inducido por la propiedad colectiva de la tierra. 4. Conclusión. 5. Referencias bibliográficas.

Cómo citar: Hall, I. (2017). De la colectividad a la comunidad. Reflexiones acerca del derecho de propiedad en Llanchu, Perú, en Revista de Antropología Social 26(2), 379-398.

\section{Introducción}

1 Professeure adjointe, Département d'Anthropologie - Université de Montréal. ingrid.hall@umontreal.ca 
Queremos mostrar en este artículo cómo la asignación de una propiedad colectiva de tierras a las comunidades campesinas en Perú, tras la reforma agraria de 1969, tuvo consecuencias sociológicas muy importantes. Aquella indujo una reconfiguración del tejido social según los límites territoriales definidos jurídicamente. Aunque muchos otros factores influyeron en los últimos 50 años, tal decisión política y legal fue esencial para las comunidades campesinas. Vamos a abordar esta cuestión, centrándonos en la dimensión generadora del derecho concerniente a los bienes comunes, tal como lo asumen Roy (Le) (2016: 613) y Gutwith y Stengers (2016: 336). Siguiendo a estos autores, consideramos que los "comunes" no pueden ser reducidos a recursos materiales y planteamos indagar los protocolos, valores y normas inventados por una comunidad para manejar sus recursos comunes (Roy (Le), 2016: 612; Bollier, 2013: 179), o sea la tierra en el caso que nos interesa. Queremos enfatizar la importancia de los lazos sociales, que Bollier y Silk (2013) estiman ser la base de los comunes, poniendo énfasis en lo que llaman "commonning", o el hecho de "hacer lo común" a una escala local. Cabe subrayar la proximidad de estas propuestas con el concepto de "comunalización" propuesto por Diez Hurtado (1998) en el caso de las comunidades campesinas peruanas.

Como lo plantean Pajuelo (2012: 136) o Diez Hurtado (2012b: 119), la idea de que las comunidades tienen como finalidad mantener la propiedad comunal se ha impuesto a través de una mayoría de autores. Aunque el caso que analizamos no pueda ser generalizable dada la heterogeneidad de las comunidades campesinas del Perú, planteamos la hipótesis de que la obtención de un título colectivo de las tierras por las comunidades campesinas del Perú en la década de 1970, dio pie a la reconfiguración de las relaciones sociales dentro de las colectividades que las recibieron. Más específicamente, nuestra hipótesis apunta a que la explotación de las tierras de propiedad colectiva indujo al establecimiento de mecanismos de regulación de la gestión de este bien común, dando lugar por ende a la creación de colectividades sociológicamente significativas, es decir, a la reconfiguración de lazos sociales dentro de estas entidades colectivas. Para ello planteamos que es esencial distinguir de un lado, la obtención del estatus jurídico de comunidad, y del otro, la organización social efectiva del grupo así delimitado tanto en lo social como en el espacio ${ }^{2}$. En otras palabras, nos interesamos en la transición de lo colectivo hacia lo comunal, inducido mediante decisión jurídica, para mostrar que este proceso se sustenta tanto en el uso compartido de prácticas, normas y valores como en la identificación de los individuos como miembros de una misma comunidad.

Esta investigación tiene una perspectiva antropológica y se basa en datos obtenidos en la comunidad de Llanchu (Calca, Cusco) sierra sur del Perú, durante largas estadías de campo entre 1998 y 2005, así como en reiteradas visitas posteriores. Esta comunidad de 70 familias fue creada después de la reforma agraria, exactamente en 1982, y como tal fue inscrita en los registros públicos en 1988. Su territorio y su población se formaron a partir de distintas entidades preexistentes a la reforma: por un lado, una parcialidad de la antigua comunidad indígena, y por el otro, segmentos de dos haciendas expropiadas por la reforma agraria. Desde cierto punto de vista,

2 Autores como Diez Hurtado (2012b: 142) y Sendón (2016: 27), que también adoptan una perspectiva diacrónica, sienten la necesidad de aclarar este punto. 
se trata de un caso relativamente marginal en la medida que la reforma favoreció de manera general muy poco a las comunidades ${ }^{3}$.

Tomando en cuenta las cifras, el número de comunidades reconocidas pasó de 2280 en 1969, o sea antes de la reforma agraria (Trivelli, 2014: 96) a 6248 en 2017 (SICCAM, 2016) ${ }^{4}$. Esto significa que el $73 \%$ de las comunidades actuales han sido creadas después de la reforma agraria, el proceso de reestructuración territorial y social que nos interesa concierne pues a la gran mayoría de las comunidades actuales. Cabe precisar que los integrantes de las comunidades campesinas peruanas representan alrededor del $20 \%$ de la población nacional, ocupan un poco más del $40 \%$ del territorio y generalmente se encuentran en una situación económicamente precaria (ver Figura 1). A pesar de esta importancia demográfica y social, este sector de la población es largamente invisible en debates públicos y políticos, ninguna política específica de desarrollo los ha tomado así mismo en cuenta (Eguren, 2013: 11; Castillo Castañeda, 2013: 15).

\begin{tabular}{|c|c|c|c|}
\hline Tipo de dato & Total & Porcentaje & Fuente \\
\hline $\begin{array}{l}\text { Número total de } \\
\text { comunidades campesinas } \\
\text { en } 2016\end{array}$ & 7267 (6138 reconocidas) & & $\begin{array}{l}\text { Directorio } 2016 \\
\text { comunidades campesinas } \\
\text { del Perú } 2016 .\end{array}$ \\
\hline $\begin{array}{l}\text { Superficie ocupada por las } \\
\text { comunidades campesinas }\end{array}$ & $\begin{array}{l}\text { 16. } 359.073 \text { ha, } 42 \% \text { de } \\
\text { la superficie del país }\end{array}$ & $42 \%$ & Censo agropecuario 2012 \\
\hline $\begin{array}{l}\text { Número de personas } \\
\text { concernidas }\end{array}$ & $\begin{array}{l}4,46 \text { millones, estimación } \\
\text { en } 1998,60 \% \text { de la } \\
\text { población rural y } 19 \% \text { de } \\
\text { la nacional }\end{array}$ & & $\begin{array}{l}\text { (Burneo Z., nd.), a } \\
\text { partir del directorio de } \\
\text { comunidades campesinas } \\
\text { del PETT de } 1998 \text { y del } \\
\text { censo nacional de hogares } \\
\text { de } 2002\end{array}$ \\
\hline $\begin{array}{l}\text { Índice de pobreza en } \\
\text { medio rural }\end{array}$ & & $\begin{array}{l}50 \% \text { en medio rural, } \\
20 \% \text { en situación de } \\
\text { pobreza extrema }\end{array}$ & $\begin{array}{l}\text { (FIDA - Fondo } \\
\text { Internacional de } \\
\text { Desarrollo Agrícola, 2013) }\end{array}$ \\
\hline $\begin{array}{l}\text { Número de comunidades } \\
\text { en la región andina del Sur } \\
\text { del país }\end{array}$ & & $\begin{array}{l}66 \% \text { (departamentos de } \\
\text { Puno, Cusco, Ayacucho, } \\
\text { Huancavelica, Apurímac) }\end{array}$ & $\begin{array}{l}\text { Directorio } 2016 \\
\text { comunidades campesinas } \\
\text { del Perú } 2016 .\end{array}$ \\
\hline
\end{tabular}

Figura 1. Algunas cifras sobre las comunidades campesinas del Perú ${ }^{5}$

La legitimidad post reforma de comunidades como Llanchu es a menudo puesta en duda con la promulgación de la ley de consulta previa (Ley 29785) en 2011. Los ex presidentes Alan García (2007) y Ollanta Humala (Remy, 2014), consideran, por

3 Las comunidades previamente reconocidas sólo obtuvieron el 7\% de las tierras expropiadas (Caballero, 1977: 148), mientras que las cooperativas recibieron el 77\% de ellas (según Chirinos-Almanza, 1975: 56).

4 Se asume que estas "nuevas comunidades" son en buena parte producto de la transformación de unidades formadas gracias a la reforma agraria (grupos campesinos, cooperativas), y a la fragmentación de comunidades mayores (Trivelli, 2014: 92-96).

5 Estas cifras toman en cuenta únicamente comunidades campesinas de la costa y la sierra, mas no las comunidades nativas de la región amazónica. 
ejemplo, que se trata de "falsas comunidades", siendo susceptibles por ello de serles negado el derecho a la consulta. En este sentido, cobran importancia los elementos que puedan sustentarlas como verdaderas entidades sociológicas o antropológicas, o sea, comunidades indígenas y originarias en el sentido de la Convención 169 de la OIT (Urrutia Ceruti, 2013).

La importancia de los bienes comunes en debates internacionales (Roy (Le) 2016; Gutwirth y Stengers, 2016), particularmente en torno a las políticas de desarrollo, se hacen igualmente sentir en el ámbito nacional peruano (Burneo Z., 2013: 231-343).

Esta conceptualización de "falsas comunidades" está inducida por la voluntad de liberalizar el mercado de las tierras producido desde los años 1990 (Castillo Castañeda, 2013; Burneo M.L., 2013: 19; Urrutia Ceruti, 2013; Diez Hurtado, 2011), conjugándose con la idealización de las comunidades tradicionales tan arraigada en la sociedad peruana. Si fueron un importante tema de estudio hasta los años 1970, las comunidades dejaron de ser una prioridad en el mundo académico, desconociéndose por ello gran parte de sus dinámicas contemporáneas (Urrutia Ceruti, 2014b: 10; Mayer, 1996) ${ }^{6}$. Inclusive hasta 2016, acceder a datos actualizados era problemático ${ }^{7}$. Los debates se encuentran polarizados (Plaza et Francke, 2014) y la posición de Fuenzalida en ellos, que las comunidades están compuestas de partes yuxtapuestas (1976: 247), es una visión que compartimos. Nuevos trabajos fueron realizados a raíz del debate sobre la ley de consulta en Perú en 2011. Autores como Diez Hurtado (1998; 2012a; 2012c), Urrutia Cerruti (2013; 2014), Castillo Castañeda (2013), Burneo Z. (2013) o Pajuelo (2012) contribuyeron ampliamente a la dinamización de aquellas reflexiones. Incluso datos disponibles, aunque deficientes, fueron actualizados.

El artículo que desarrollamos a continuación está organizado bajo la estructura siguiente: en un primer momento precisaremos los conceptos utilizados en el estudio. Luego nos detendremos en el caso de la comunidad de Llanchu, presentaremos su historia así como las diferentes formas de aprovechamiento de la tierra que la definen. Sobre esta base, en una tercera parte demostraremos cómo la propiedad colectiva de la tierra induce un control social sobre los miembros de la comunidad.

\section{Precisiones teóricas, conceptuales e históricas}

Este enfoque se basa en una perspectiva dinámica de las comunidades y se inspira muy particularmente en el trabajo de Balandier (1985). El concepto de "comunalización” propuesto por Diez Hurtado $(1998,2012 a)$ en el Perú va en esta dirección y nos parece particularmente pertinente. Por otra parte, el autor define primero que nada las comunidades campesinas peruanas contemporáneas como "conjuntos campesinos que comparten la propiedad de un territorio" (Diez Hurtado, 1998: 9); añadiendo "que mantienen determinados lazos de parentesco y reciprocidad y que cuentan con una dirigencia comunal encargada de gestionar y administrar algunos de los recursos y de representar al conjunto frente al exterior" (Ibid.). Diez Hurtado

Sobre la historia de la antropología andina y peruana se puede consultar a Degregori (2012) y Salomon (2012), dos síntesis recientes.

El Instituto del bien común (IBC) y el Centro peruano de estudios sociales (CEPES) crearon en 2015 el Sistema de Información Sobre Comunidades campesinas del Perú con un directorio de comunidades campesinas del Perú (SICCAM, 2016). 
también especifica que "la identidad y unidad del grupo se enraízan en la memoria de una (reciente) historia común y se refuerzan por la participación de sus miembros en ciertos ritos y practicas cívicas, lúdicas y religiosas" (Ibid.). Así que la dimensión histórica de las comunidades es relativizada. Por último, insiste en que "los grupos campesinos así definidos se hallan inscritos en una sociedad nacional (y regional) a la que pertenecen y que les impone un sistema de normas, dentro de las cuales interactúan y se desarrollan" (Ibid. $)^{8}$. Este enfoque nos parece muy pertinente en la medida que es profundamente sociológico, pone en evidencia la importancia del acceso a la tierra, pone en entredicho la importancia de la profundidad histórica de las comunidades y reubica la existencia de estos grupos en un marco normativo y jurídico nacional históricamente definido.

Algunas precisiones terminológicas y conceptuales son imprescindibles, ya que ambos términos tienden a ser confusos cuando se trata de la propiedad y manejo de bienes comunes (Chamoux y Contreras, 1996; Roy (Le), 2016; Ostrom y Hess, 2007). La terminología que aquí empleamos proviene del trabajo de Elinor Ostrom. Nos basamos muy particularmente en el texto, escrito con Hess (2007), en el que los dos autores retoman y explicitan una tipología de "sistemas de derechospropiedad" (property-rights systems) propuesta por Schlager y Ostrom de 1992 (Ostrom y Hess, 2007: 12). Esta terminología permite a los autores relativizar la importancia de los títulos de propiedad y destacar la importancia del pluralismo jurídico o de los "paquetes de derecho" (bundel of rights) (Roy (Le), 2016: 615). Este sistema de derechos de propiedad deriva en efecto de corpus legales diferentes. Estos autores hacen una distinción entre la propiedad de jure, plasmada en un título de propiedad, y la propiedad de facto ejercida efectivamente por los usufructuarios del recurso que manejan colectivamente, también llamada jurisdicción (Diez Hurtado, 2012b: 116) o derechos de uso (Chamoux y Contreras, 1996: 16). En efecto, la propiedad colectiva no implica la gestión colectiva de todos los recursos y de todo el espacio, es decir, la propiedad de facto. Como los autores muestran, esta última combina a menudo usos colectivos e individuales. Para caracterizar estos sistemas de derechos de propiedad-derecho, Ostrom et Hess proponen cinco criterios que detallaremos ulteriormente al describir el caso de Llanchu. Más particularmente, nos interesamos en los bienes comunes manejados por comunidades, al igual que Agrawal (2003), Ostrom, (2001) Agrawal y Gibson (2001) o Contreras y Chamoux, (1996).

Para situar los términos del debate de una manera rápida y minuciosa, diremos que la gran mayoría de comunidades campesinas peruanas presentan un título de propiedad colectiva reconocido. Sin embargo, esto no significa que todas estas tierras sean explotadas comunalmente; de hecho, la mayoría de ellas son explotadas por familias que disfrutan casi de una propiedad individual sobre ciertas parcelas - esencialmente aquellas que disponen de riego - mientras que otros espacios están, por el contrario, bajo el control de la comunidad - generalmente pastizales ${ }^{9}$. Es importante destacar que, por su carácter montañoso, el territorio de las comunidades en regiones andinas está escalonado, distinguiéndose diferentes zonas de producción (Murra, 1985).

\footnotetext{
Diez Hurtado muestra en el caso de la comunidad de Catacaos (Piura, costa Norte del Perú) cómo va evolucionando la propiedad de la tierra y el control de su uso de manera histórica $(1999 ; 2012 b)$.

$9 \quad$ Para un minucioso análisis agroeconómico referirse a Kervyn (1989).
} 
La obtención de una personería jurídica y de un título de propiedad de las tierras es el fruto de un largo proceso que vamos a esbozar rápidamente. Antes de la colonización, la población local estaba organizada en ayllu ${ }^{10}$, este carecía de propiedad individual de las tierras, el colectivo procedía a redistribuciones periódicas de tierras en función de las necesidades de cada familia (Rostworowski, 1962). Con la conquista española las comunidades — como forma de organización social—estuvieron de alguna manera protegidas por el "pacto colonial', ya que estas pagaban tributo y proporcionaban mano de obra al Estado colonial (Castillo Castañeda, 2013: 18). A través de la defensa de sus bienes comunes, o sapci, las tierras quedaron relativamente resguardadas (Puente Lima (de la), 2015). Al inicio del periodo republicano y de acuerdo a su proyecto liberal, Simón Bolívar privatizó las tierras de las comunidades; pero la desastrosa situación a la que condujo su decreto lo llevo a retractarse $\mathrm{y}$ restaurar rápidamente la protección colectiva de las tierras de las comunidades. Es durante esta época que las haciendas, invadiendo comunidades vecinas, empiezan a expandirse de manera considerable (Glave Testino y Remy, 1983).

Un paso importante fue franqueado el año 1920. En efecto, ante la preocupante situación que mostraban las poblaciones de comunidades, el presidente Augusto B. Leguía reconoció jurídicamente las llamadas "comunidades indígenas" a través de una nueva constitución (Castillo Castañeda, 2013: 20). Se instaura un estatuto legal y se establece un registro de comunidades. Las tierras de las comunidades indígenas devienen así inembargables. Gracias a la constitución de 1933 estas últimas se ven reconocidas como persona jurídica; y sus tierras además de inembargables pasan igualmente a ser inalienables e imprescriptibles. Gradualmente, el número de comunidades inscritas en este registro será cada vez más notable (Trivelli, 2014). La comunidad Pampallaqta Baja, de la cual Llanchu fue un anexo, ha sido reconocida en este período. Esta situación se mantuvo hasta 1969 cuando el presidente Velasco Alvarado, vía una reforma agraria, expropió las grandes haciendas, redistribuyó la tierra y reestructuró las comunidades - de adelante llamadas "Comunidades campesinas"- mediante un estatuto especial (Decreto supremo No. 37-70 A). Las comunidades campesinas, aunque no se beneficiaron casi de la redistribución de tierras, vieron confirmada su personería jurídica y las que estaban debidamente inscritas en registros públicos recibieron títulos de propiedad de sus tierras. De esta manera, el régimen de posesión y la tenencia de la tierra fueron reestructurados entre los años 1970 y 1990, así mismo las condiciones de existencia de la población campesina se transformaron de manera profunda. Al liberar las tierras de las haciendas, la reforma agraria dio impulso a nuevas normas en la vida de las comunidades.

Con la voluntad de liberalizar el mercado de tierras a partir de los años 1990, se modifica el régimen de protección de la tierra de las comunidades (Burneo M.L., 2013; Burneo Z., 2013: 22; Castillo Castañeda, 2013: 197). La ley de reforma agraria es derogada en 1991. Si el territorio de las comunidades sigue siendo imprescriptible, con la constitución de 1993 pierden su carácter inembargable e inalienable. Esto per-

10 El término ayllu, de origen quechua, es polisémico en el uso corriente, suele ser utilizado para referirse a un grupo de parentesco o a un territorio (Nobuyuki, 1981). En medios académicos es empleado para referirse a las comunidades prehispánicas (Castro Pozo, 1973), o para subrayar una continuidad a largo plazo; en muchos casos, su uso conlleva un posicionamiento político como es el caso de Castro Pozo o actualmente de Gacía Linera en Bolivia (2005) que habla del "ayllu del siglo XXI". Otros autores lo utilizan en trabajos recientes, Sendón (2016) para enfatizar la importancia estructural del parentesco y De la Cadena para resaltar las especificidades de la ontología andina (2015). 
mitió favorecer a las industrias extractivas (Yeckting Vilela y Ramírez Zapata, 2012) así como a la agroindustria, especialmente, en la costa (Burneo M.L., 2013: 22).

Aunque todas estas medidas, y otras más recientes como la Ley de tierras $\left(\mathrm{N}^{\circ}\right.$ 30230) del 2014, no cambiaron de manera determinante la situación de las comunidades, especialmente de la Sierra (Burneo, 2012: 216-217), crearon eso sí un contexto de debilitamiento de la institución comunal. El $60 \%$ de la población campesina está a favor de una individualización de la propiedad (encuesta del CEPES, 2003); sin embargo, y aunque parezca paradójico, también lo está a favor del mantenimiento de las comunidades (Burneo Z., 2013: 214-215). Contrariamente a un a priori extendido, para los campesinos la propiedad colectiva no se encuentra en oposición con la puesta en entredicho de la comunidad. Más allá del beneficio económico inducido por la regulación del acceso a la tierra y el control de la producción que Kervyn pone en evidencia (1989), y tal como lo muestra Diez Hurtado (citado por Burneo Z. 2013: 221), la función de regulación social de la comunidad explicaría en gran medida el apego por lo comunal. En efecto, como pudimos igualmente constatar de nuestro lado, los miembros de las comunidades de la zona andina consideran que esta institución es una fuente importante de seguridad (Burneo Z., 2013: 223).

\section{La comunidad campesina de Llanchu, formación y organización agraria}

La población de Llanchu se considera hoy en día, netamente campesina y comunera, es decir, el sector rural que se encuentra bajo la normatividad inducida por el estatuto de comunidad campesina.

\subsection{La obtención de la propiedad de la tierra, un objetivo primordial}

La obtención de la propiedad de la tierra fue desde un punto de vista histórico, primordial para los comuneros de Llanchu al igual que para otras comunidades peruanas. Cotler pudo constatarlo por ejemplo en Huarochiri (en Pajuelo, 2012: 136) y Diez Hurtado en Catacaos (2012b). Aunque obtuvieron mucho más, para los campesinos de Llanchu, se trató ante todo de hacer respetar derechos de propiedad de facto, es decir un título de propiedad. Esta meta fue tan importante que hizo que enemigos de antaño: los aylluruna (gente del ayllu de Llanchu) - y haciendaruna (gente de las haciendas vecinas) se unieran en torno a ella. En efecto los miembros del ayllu de Llanchu, se organizaron a fin de "reivindicar" ${ }^{11}$ las tierras colindantes de las haciendas de Machacancha y Huamanchoque. En este proceso, de 1960 a 1988, la "gente de las haciendas" (haciendaruna) buscó proteger sus intereses, que por otro lado coincidían con aquellos del representante local del hacendado (el arrendatario). El antagonismo entre estos últimos y la "gente del ayllu" quedó acentuado hasta que las tierras de las haciendas pudieron finalmente ser expropiadas y entregadas a la comunidad. Esto fue realizado a nombre de la comunidad madre de Pampallaqta Baja, de la cual y según documentos coloniales del siglo XVII Llanchu ayllu era una parcialidad. Sin embargo, fue una etapa transitoria y Llanchu fue creada como

11 El uso de este término es contrapuesto al de "adjudicación”, procedimiento por el cual el gobierno expropió las haciendas para adjudicarlas a otras entidades, generalmente cooperativas. Los comuneros de Llanchu subrayan así su protagonismo en el proceso. Esta historia no es fácilmente referida en público (Hall, 2013). 
comunidad autónoma en 1988, cuando la "gente del ayllu" de Llanchu pactó con los ex-trabajadores de las haciendas. Los lazos fueron muy probablemente frágiles entre Llanchu y la comunidad madre por la dispersión de las tierras de las haciendas en su territorio inicial. Al cabo de este proceso, la comunidad de Llanchu obtuvo personería jurídica así como la propiedad de las tierras.

La reforma agraria preveía que la tierra iría a "los que trabajan", lo que suponía su redistribución entre los miembros de la comunidad. No obstante, esta no se redujo a nivel comunal. Según las encuestas, cada uno de los comuneros encontró sus derechos anteriores confirmados. Las familias del ayllu conservaron sus derechos sobre el territorio que desde entonces pasó a llamarse "sector Llanchu", sucediendo lo mismo con la gente de las haciendas. A pesar de los discursos que oponen a los aylluruna frente a los haciendaruna, muchos campesinos del ayllu lograron tener acceso a tierras en la hacienda. Esperando la reforma agraria, los arrendatarios terminaron muy solicitados como padrinos (de matrimonio o bautismo) por parte de los comuneros; esta estrategia les permitió "agarrar terrenos" de los cuales nunca más se desprendieron. A pesar de lograrlo, aquellos que las obtuvieron en condiciones poco ventajosas optaron por irse de Llanchu. Las tierras no adjudicadas, ya sea porque eran pastizales como la parte baja del sector Llanchu, o porque eran cultivadas por la hacienda, pasaron a ser tierras comunales. Sin embargo, dos años más tarde se decidió "parcelizarlas", de manera que cada familia pudiera tener su vivienda en la parte baja. Por los años 90, parte de la estrategia era lograr la electrificación de la zona, algo que solamente se hizo efectivo en el 2004. No obstante, muchas familias no construyeron nuevas viviendas, sino que cultivaron las parcelas que poseían riego. Las tierras de los pisos superiores fueron entregadas a los jóvenes al inscribirse en la comunidad. Esto muestra hasta qué punto, y a pesar de la propiedad colectiva legalmente instituida, la gente tenía otro concepto respecto a la gestión de la tierra. Todas las tierras colectivas fueron rápidamente atribuidas. Los campesinos querían acceder de manera más individualizada a las parcelas y las que disponían de riego eran por supuesto las más preciadas. El ideal campesino de uso de la tierra no era colectivo sino más bien familiar y en este aspecto el caso de Llanchu sería una confirmación (Kervyn, 1989; Diez Hurtado, 2012b).

Como resultado del proceso, una unidad territorial fue diseñada por las autoridades gubernamentales. Sobre esta base se creó una "comunidad campesina" — como unidad administrativa - y los que hasta entonces ocupaban el territorio se acomodaron (respetando los frágiles derechos anteriores), formando en este marco una nueva estructura social. En este caso, la propiedad de la tierra condicionó el grupo social que luego se consolidó alrededor de la comunidad de Llanchu.

\subsection{De la propiedad colectiva de las tierras a su uso familiar}

La pertenencia de los pobladores de Llanchu a su comunidad se concreta a diario, pues como veremos, se dedican a las actividades productivas en las que la comunidad es un actor de regulación esencial: la agricultura y el pastoreo. Si los datos describen el sistema imperante entre 2004 y 2005, planteamos que son el resultado de un doble proceso dinámico, tal como muestran Guillet (1979:48-83), Seligman (1995: 128-154) y Diez Hurtado (2012b). Pondremos así mismo en evidencia, al igual que Eguren, Del Castillo y Burneo (2009: 33) y Diez Hurtado (2012b), la importancia que tiene la pluralidad jurídica, es decir, leyes, reglamentos, así como 
"usos y costumbres"12. Nos interesamos más específicamente en la normatividad local de la gestión de las tierras no escrita pero sí enmarcada en las reglas del derecho positivo, y en aquellas normas que afectan la estructuración social de la comunidad $\mathrm{y}$ el estatus de las personas en ella.

En Llanchu como en otras partes del mundo, según apuntan los estudios de Ostrom (1990) y aquellos editados en Agrawal y Gibson (2001), la propiedad colectiva de la tierra no es equivalente de uso común. Para entenderlo, Ostrom y Hess (2007: 16) analizan los diferentes "sistemas de derechos-propiedad" (property-rights systems) descomponiéndolos en cinco derechos: acceso, retiro (withdrawal), manejo, exclusión y alienación (ver Figura 2). Estos criterios permiten, a nuestro parecer, detallar los tipos y el grado de jurisdicción o apropiación que les corresponde para retomar la terminología más difundida en la literatura tratando del Perú (Diez Hurtado, 2012b: 116; Burneo Z., 2013: 162).

\begin{tabular}{|l|l|}
\hline \multicolumn{1}{|c|}{ Tipo de derecho } & \multicolumn{1}{c|}{ Definición } \\
\hline (1) Acceso (Access) & $\begin{array}{l}\text { Derecho al acceso a una área física definida y a disponer de } \\
\text { beneficios no substractivos (por ejemplo, caminata, canoa, } \\
\text { sentarse al sol) }\end{array}$ \\
\hline (2) Retiro (withdrawal) & $\begin{array}{l}\text { El derecho a obtener unidades de recursos o productos de } \\
\text { un sistema de recursos (por ejemplo, atrapar peces, desviar } \\
\text { agua). }\end{array}$ \\
\hline (3) Manejo (management) & $\begin{array}{l}\text { El derecho a regular los patrones de uso interno y } \\
\text { transformar el recurso mediante mejoras. }\end{array}$ \\
\hline (4) Exclusión (exclusion) & $\begin{array}{l}\text { El derecho a determinar quién tendrá derechos de acceso } \\
\text { y derechos de retirarse, y cómo estos derechos pueden ser } \\
\text { transferidos. }\end{array}$ \\
\hline (5) Alienación (alienation) & $\begin{array}{l}\text { El derecho a vender o arrendar derechos de gestión y } \\
\text { exclusión }\end{array}$ \\
\hline
\end{tabular}

Figura 2. Tipos diferentes de derechos, de acuerdo a Schlager y Ostrom (1992 citado en Ostrom y Hess, 2007:16).

Debido a la topografía distinguimos en la zona andina pisos agroecológicos diferentes, también conocidos como áreas de producción (Murra, 1985): mientras que la tierras más bajas están destinadas a la agricultura, las tierras más altas se reservan a la cría de animales. Estos usos diferenciados inducen limitaciones en la gestión de la tierra, particularmente por la restricción en el uso de parcelas para el pastoreo durante gran parte del año. Por lo que derechos individuales y colectivos se combinan en función del área de producción.

La comunidad de Llanchu está ubicada entre los 3600 y 5000 metros de altitud. Las zonas bajas de su territorio — a menos de $3800 \mathrm{~m}$ de altura- están comprendidas en el piso agroecológico llamado quechua. Las extensiones dedicadas a la agricultura en esta zona se sitúan generalmente cerca de fuentes fluviales, que además presentan un relieve casi llano. Siendo esta zona propicia para la agricultura, allí se

12 Reconocidos con la reforma del estatuto de comunidades de 1991 (DS Nº 008-91-TR) en el artículo 28. 
construyeron andenes ${ }^{13}$ y canales de riego. En estas partes anualmente se cultivan ciertos tipos de maíz amarillo, papas mejoradas, pasto y hortalizas. Cada parcela (chacra) es usufructuada por las familias que componen la comunidad: cada grupo familiar dispone aproximadamente de una hectárea y decide el tipo de siembra al cual esta será destinada. Aunque informalmente, también se pueden arrendar a terceros. En la práctica y solamente hasta cierto punto, este usufructo se presenta como un derecho individual de propiedad ejercido en nombre del jefe de hogar. Se considera que la comunidad debería ofrecer tierras de este tipo a cada joven que se inscribe en sus nóminas; pero no es el caso como veremos más adelante. Probablemente se hizo esto inoperante desde hace mucho tiempo, si algún día fue realmente puesto en práctica. Llanchu no posee en este piso tierras comunales dedicadas a la agricultura.

En el piso agroecológico superior, llamado suni, entre los 3800 y $4000 \mathrm{~m}$ de altura, se cultivan mayormente variedades nativas de maíz, así como ciertos tipos de quinua, cebada y arvejas. Este nivel cuya pendiente se hace particularmente más pronunciada por la falta de andenes, tampoco presenta sistemas de riego de manera significativa. Aunque cada familia se beneficia aproximadamente de una hectárea, el manejo colectivo impone restricciones ya que las parcelas son incluidas en un sistema de rotación. Ciertos sectores son destinados cada dos años al pastoreo (mayormente de ovinos). Esta medida permite fertilizar las tierras sin que los animales arruinen los cultivos. Como en el piso inferior, cada familia dispone de "sus" tierras, solo que aquí se deben tomar en cuenta las decisiones comunales para su manejo. Cada joven que se inscribe en la comunidad tiene acceso a parcelas de este tipo. Llanchu tampoco presenta parcelas comunales en este piso.

Finalmente en un nivel más alto aún, por encima de los 3800 metros de altura, se ubica el piso ecológico puna. Allí se encuentran las parcelas dedicadas al cultivo de los tubérculos, sobre todo, papa, oca o mashwa así como sectores para el pastoreo, cuando el pasto escasea en los niveles inferiores. Estas parcelas tienen un ciclo de rotación de 7 años: 2 de cultivo y 5 de descanso. Cada familia siembra allí pequeñas parcelas que juntas apenas llegan a la hectárea y media. Los jóvenes miembros de la comunidad reciben igualmente parcelas en este piso. Hasta el 2005, existían en el piso puna parcelas colectivas en las que se producían alimentos consumidos en actos comunales o para la venta. Poco interesados en trabajarlas, los campesinos dejaron de cultivarlas debido en gran parte a los drásticos cambios que desde entonces comenzó a experimentar el mundo rural ${ }^{14}$.

El caso de Llanchu muestra que el uso de las tierras se organiza mayormente a nivel del grupo familiar y que las parcelas colectivas han desaparecido prácticamente de la comunidad. Las potencialidades agro-ecológicas de acuerdo al piso ecológico influencian la importancia de lo colectivo en el manejo de las parcelas: la necesidad de proteger los cultivos de los animales induce a la toma de decisiones colectivas para los sectores que son labrados. Tomando en cuenta el piso ecológico, la comunidad también está en disposición de entregar o no tierras a un joven y su familia que se incorpora a ella. Las tierras del piso quechua, situado en la parte más baja y con mayor potencial agrícola no pueden ser atribuidas bajo esta forma. Para acceder a

\footnotetext{
Término utilizado en el Perú para designar a los bancales.

La depreciación de la papa, aunada al incremento del costo de la carne contribuyeron en parte a estos cambios. Por otra parte, las actividades agrícolas ya no constituyen la única fuente de ingresos pues han surgido otras alternativas como el trabajo asalariado en las minas o las oportunidades que brinda la actividad turística.
} 
ellas, se necesita obtenerlas por canales diferentes, es decir por medio de una "transferencia" de padres a hijos ${ }^{15}$.

La familia aparece entonces como una unidad clave en términos de gestión de la tierra. Por dicho término se entiende generalmente una pareja de esposos y su prole. Si el sistema de parentesco es bilateral, tiene una inflexión patrilineal que se refleja entre otras cosas a través del padrón de residencia virilocal. Para la asamblea comunal, órgano supremo de la comunidad, cada hogar es representado en la arena política por el jefe de familia. En la gran mayoría de los casos, son los varones "hijos de la comunidad" quienes pueden elevar una demanda para inscribirse en el padrón como miembro activo de la comunidad. En función de sus necesidades y posibilidades de acceder a las tierras a través de sus padres, se les atribuirá tierras en los pisos superiores. Dicho esto, para acceder a las tierras uno debe forzosamente devenir miembro de la comunidad. El reglamento de la ley general de comunidades ${ }^{16}$ indica que los miembros de estas deben habitarlas (artículo 23.b) y explotar la(s) parcela(s) que se les ha concedido de manera directa (artículo 27.e), o sea que deben vivir de sus actividades agrícolas. Luego, ser comunero da derecho a tener acceso a la parcela familiar y al uso de los pastos naturales (Articulo 25.h). Resulta entonces que para ingresar oficialmente en la comunidad (como comunero calificado) uno debe obtener de manera propia en Llanchu acceso a tierras de regadío, es decir, heredando los derechos de usufructo de los padres mediante una "transferencia". Esto remite en parte la pertenencia a la comunidad a dinámicas familiares y no colectivas, las cuales se manifiestan ya en un segundo momento. Hemos podido constatar que si alguien deviene comunero cuando recibe tierras, deja de serlo de manera activa cuando ya no las tiene ${ }^{17}$. Los padres de familia se quedan entonces con los derechos sobre las tierras hasta su retiro de la vida activa. Esto les permite mantener un estatus dentro de la comunidad, y también saber cuál de los hijos (o de las hijas) permanecerá en la comunidad para poder entregarles el derecho de usufructo. Hasta entonces los miembros de una familia trabajan las tierras en forma colectiva y en función de las necesidades de cada uno. Una pareja puede entonces recibir derechos sobre parcelas con riego relativamente tarde, o sea cuando cumplan 45 años. Percibimos aquí hasta qué punto el uso de las tierras está ligado al sistema social: acceder a la tierra, sobre todo a parcelas con riego, significa obtener un estatus social. Transferir sus derechos sobre tierras con riego significa dar el derecho de quedarse en la comunidad y de volverse un verdadero miembro de la comunidad.

Se hace evidente que la mayoría de las tierras agrícolas y los pastos se encuentran bajo un régimen de propiedad familiar. Los derechos de propiedad ejercidos por las familias corresponden, aunque no siempre de manera completa, a tres de los cinco criterios propuestos por Ostrom y Hess (2007: 16). Estos son 1) el acceso a la tierra, 2) el retiro o posibilidad de beneficiarse con los recursos de estas parcelas (withdrawal) y 3) el manejo de la tierra. En cuanto a este último criterio existen variaciones que obedecen al piso agroecológico. Si en las parcelas más bajas las familias tienen amplia libertad para decidir el uso que podrán darles, en aquellas a mayor altura estarán sometidas a las consignas comunales. Los criterios 4) exclusión

\footnotetext{
Al respecto, Burneo Z. (2013: 173) subraya la falta de datos.

16 El Decreto supremo 24656 de 1991, que actualiza el Estatuto especial de comunidades campesinas promulgado con la reforma agraria.

17 Lo que significa que no tiene obligaciones como la de trabajar en las faenas o de participar en las asambleas.
} 
y 5) alienación, por su parte, no competen del todo a las familias de Llanchu. Como colectivo la comunidad tiene la última palabra, no obstante las familias de manera informal muestran un decisivo papel en el futuro de la comunidad: mediante la transferencia de tierras con riego cada familia determina quién llegara a ser parte de la comunidad. El control comunal induce allí criterios propios sobre los cuales se tiene un consenso: los que quieren transferir tierras y los que deberían recibirlas deben de haber respetado la comunidad sirviéndola, o mostrando un aporte en el futuro. Esto muestra hasta qué punto la normatividad local se inspira en valores socio-culturales muy importantes en el mundo rural-campesino andino, es decir, el valor del trabajo y la importancia del sistema de cargos. Para nosotros, ahí radica precisamente la articulación entre los derechos individuales y comunitarios.

\section{El control social inducido por la propiedad colectiva de la tierra}

Como lo vamos a mostrar ahora, estas competencias colectivas - la posibilidad de decidir quién va a beneficiarse de una parcela y bajo qué forma (exclusión-criterio 4) y poder vender o alquilar una parcela (alienación - criterio 5) — están muy ligadas al control social comunal. En efecto, si el usufructo de la tierra es atribuido a cada familia, la colectividad tiene oficialmente competencia para manejar el acceso a ella. Esto se manifiesta de diversas formas, según el estatus de cada uno de los miembros de la comunidad. Sin embargo, para ello se tiene que comprender que el acceso a la tierra es una contraparte que induce obligaciones. Estas obligaciones son formalizadas por los campesinos de Llanchu bajo el término de "servicio a la comunidad", las cuales varían según el estatuto del usufructuario en la comunidad. Esta prestación tiene dos componentes: la participación en las labores comunales o faenas, y la participación en la vida político-administrativa de la comunidad. Estas dos nociones se revelan claves e interconectadas en la medida que permiten apreciar el "respeto - [que cada comunero manifiesta hacia] a la comunidad". En efecto, el respeto es el valor central de la vida social en Llanchu como comunidad, y permite articular la jerarquía local con la distribución del poder político. El respeto se adquiere a través del "servicio a la comunidad", por eso las personas que tuvieron y tienen un papel preponderante en la comunidad son considerados como "hombres de respeto" (en quechua respetoyuq).

La importancia del trabajo comunal se hace evidente en el caso de los llamados hawasani o personas que, habiéndose ido a vivir fuera de la comunidad, tienen a sus padres en ella como miembros, manteniendo así el derecho de explotar sus parcelas. Los hawasani no son comuneros activos, o sea "no tienen ni voz ni voto" como se suele decir. Esto significa que aunque participan de ciertas actividades, no pueden manifestar opinión alguna en asamblea o emitir su voto. La condición principal para gozar del usufructo es participar "puntualmente" en las faenas. De lo contrario pueden perder los derechos que ejercen sobre la tierra de sus padres. Las faenas consisten sobre todo en la edificación de obras comunales, limpieza de los canales, el mantenimiento de la carretera o la participación en las tareas de un proyecto de desarrollo comunal. A inicios de los años 2000, había aproximadamente una quincena de faenas por año. Programadas con solo días de anticipación, la posibilidad de informar a los hawasani de su realización es problemática en la medida que residen fuera de la comunidad. Incluso ahora que el uso de teléfonos celulares se ha 
hecho común, pues la cobertura no es disponible de manera permanente. Aun así, si estuvieran al tanto, les resultaría difícil liberarse de sus propias actividades para asumir personalmente tales responsabilidades. Conscientes de que si no lo hacen, perderán sus derechos, los hawasani recurren a la minga para tomar parte en la faena a través de terceros. Esta forma de reciprocidad se establece, por lo general, entre dos personas con lazos de parentesco. A diferencia del ayni que es una forma de reciprocidad simétrica, donde el trabajo se intercambia con trabajo, la minga es asimétrica, es decir, que la contraparte puede ser diferente a lo ofrecido e incluso tomar la forma de una remuneración o jornal. Los hawasani, al servirse de la minga, dan apariencia de reciprocidad al trato monetario que establecen con su contraparte para hacer frente a los requerimientos de una faena comunal. No obstante, este proceder queda generalmente al descubierto en la asamblea, quien se guarda de hacérselo saber en su debido momento. En efecto, la participación en las faenas es verificada cada dos años, en el momento preciso que se actualiza el padrón de la comunidad y la posición de sus miembros. La situación de los hawasani deviene muy delicada en esos instantes. Al conocerse que estos envían trabajadores para representarlos en las faenas, la asamblea no valida su participación dándoles a entender que lo hecho es insuficiente. El mensaje es el siguiente: tienen que participar ustedes en persona. Lo que cuenta no es realizar el trabajo sino "trabajar para [su] comunidad". Esta situación conduce a los hawasani, que como dijimos no tienen "ni voz ni voto" en la asamblea, a recibir una amonestación humillante por parte de la directiva. Al final, los hawasani terminan pagando una multa cuyo monto representa lo dispensado en la minga. Ellos saben, como pudimos constatar personalmente, que corren el riesgo de perder simplemente sus derechos. Estas son justamente las condiciones para mantenerlos. En el año 2000, cada hawasani tenía que lidiar individualmente con la asamblea; pero ahora - con las migraciones alentadas entre otras cosas por el boom minero - se han organizado en distintas comunidades del departamento del Cusco "comité de residentes"18. Esto les permite negociar colectivamente derechos sobre una vivienda y/o parcelas a cambio del pago de cuotas. El ejemplo de los hawasani muestra la importancia que tiene "trabajar para la comunidad" a través de las faenas, un componente cardinal del "servicio a la comunidad" que cada uno debe brindar. Lo que importa, además, no es la cantidad de trabajo, sino el lazo que implica el hecho de trabajar. La propiedad colectiva de la tierra permite a la asamblea comunal anular si lo consideran los derechos sobre la tierra, permitiéndoles a su vez ejercer un control eficaz sobre los hawasani.

Para los miembros activos - los que residen en la comunidad, viven de actividades agropecuarias y están oficialmente inscritos en el padrón- la participación en las faenas es importante y muy considerada, pero constituye solo una parte del servicio que se les exige. Se espera que participen en la vida política-administrativa de la comunidad asumiendo diferentes cargos los cuales constituyen un sistema en sí1 ${ }^{19}$. Estos cargos son regidos por dos principios: son rotativos (deben renovarse periódicamente, 2 años en el caso de la Junta directiva), y deben ser ascendentes (asumir cada vez un cargo de mayor responsabilidad). Según las observaciones y entrevistas

18 Este dato ha sido mencionado por el equipo de Área de Gobernabilidad y Justicia Intercultural del Centro Bartolomé de las Casas en Cusco, y más especialmente por Wilfredo Fernández, Juan Churats y Juan de Dios Condori con quienes nos entrevistamos en julio de 2016. Les agradecemos por compartir su tiempo y experiencia.

19 El tema de los "sistemas de cargos" es clásico en la antropología mesoamericana y andina. Para una síntesis consultar al respecto el trabajo de Pérez Galán (2004). 
recogidas, se comienza con cargos menores, aportar por ejemplo chicha o cerveza de maíz para todos los presentes, continuando con responsabilidades aún más importantes, como organizar labores colectivas (asumiendo el cargo de mandón), desempeñar un rol en los comités especializados (gestión del agua potable o del riego), asumir luego cargos en la Junta directiva (en este orden: vocero, secretario, tesorero y presidente) hasta ocupar finalmente responsabilidades en el comité electoral ${ }^{20}$. En este sentido la persona no solicita un cargo, sino que se le atribuye, significando con ello que la colectividad reconoce que la persona aludida está en posición de mostrar las capacidades correspondientes. En efecto, un comunero no decide presentarse a un cargo, sino que más bien es propuesto por sus compañeros para poder desempeñarlo. Evidentemente, cada propuesta debe estar debidamente sustentada por otras personas más. Como suele decirse en la comunidad "la gente sabe, la gente evalúa" a "quien le toca" un cargo.

Dicho esto, no se ha visto ni escuchado del caso de comuneros activos que perdieron sus derechos sobre la tierra. Aunque eso sí, represalias simbólicas fueron tomadas en contra de individuos que no sirvieron a la comunidad de manera adecuada, provocando su recalificación en el orden jerárquico del padrón. Sin embargo, pudimos constatar que se suelen tomar medidas adecuadas cuando una persona que se "jubila"21, desea "transferir" a sus hijos el usufructo de sus parcelas. Dado el estatus de la tierra, la asamblea comunal debe ratificar o no esta "transferencia". Esto es una oportunidad de la colectividad para ejercer su control. Para estudiar una demanda de transferencia, la asamblea evalúa la calidad del "servicio a la comunidad" que brindaron las dos partes (el que da y el que recibe), cualidad que se considera como expresión de "respeto [hacia] la comunidad".

El uso de esta terminología entra en resonancia con el respeto que los hombres deben acumular cumpliendo con sus obligaciones. Acceder al uso de la tierra en esta comunidad está íntimamente ligado a una lógica social y cultural específica que vamos a presentar ahora. Mostraremos cómo la emergencia de la comunidad de Llanchu como unidad sociológica fue promovida por la propiedad colectiva de la tierra, y cómo el control de este patrimonio colectivo indujo la reproducción de un cierto orden social.

Para entenderlo hay que analizar los principios que rigen la estructura social de la comunidad, expresados de manera clara durante las asambleas comunales. Durante estas reuniones de carácter mensual, se decide la vida comunal y la gestión de los recursos. Los varones representan a sus hogares, el orden de su inscripción en el padrón comunal corresponde a su posicionamiento en la jerarquía social, la cual refleja a su vez la participación de cada uno en los debates públicos y la repartición del poder.

En cuanto a los "jubilados": ¿qué condiciones permiten "transferir" sus tierras a los hijos?, ¿de qué manera se toma tal decisión? El análisis del funcionamiento de la asamblea comunal permitió mostrar la importancia de un grupo reducido de personas ( 3 por 70 familias en 2005) cuyo papel en la Asamblea es central para la toma de decisiones: los oradores, vozniyuq o parlaqkuna. Ellos expresan su parecer sobre cada tema abordado y formulan las decisiones que el presidente validará luego.

20 Ya demostramos en otro trabajo que estos cargos administrativos han sido incorporados al sistema de cargos en Llanchu (Hall, 2016: 99).

21 Este término no implica recibir una pensión, sino que coincide con el hecho de dejar de ejercer en nombre propio el derecho al usufructo de las tierras, significando que la persona ya no está obligada a participar en las actividades comunales (faenas, asambleas, cargos administrativos). 
Si en principio esto les otorga cierta potestad, ello no debe interpretarse como una forma de concentración de poder por parte de unos pocos individuos. En efecto se espera que no lo ejerzan con fines personales. De manera que proceden estas personas bajo la supervisión de los mayores (kuraq) teniendo que demostrarles, así como a los demás miembros de la asamblea, que son portadores de lo que se suele llamar la "voz de la comunidad". Significa esto que no deben tomar decisiones en función de sus propias opiniones, sino que estas deben basarse en las de los demás. Tienen que tomar en cuenta en primer lugar la opinión general de la asamblea expuesta en los debates públicos, es decir, las intervenciones formales en la asamblea, así como los comentarios en las conversaciones informales entre grupos más reducidos durante dichas discusiones. Por otro lado, tienen que tener presente las normas éticas manejadas en la comunidad, de las cuales los más ancianos (kuraq) son los garantes. Durante estos debates, diferentes procedimientos oratorios tienen un efecto muy significativo: la "comunidad" aparece como un actor en los discursos, se hace presente como una entidad moral de referencia que se debe "respetar" (Hall, 2016). Este valor, el respeto, se hace presente mediante los oradores para regir las relaciones sociales. Un hombre desarrolla su vida social y política mostrando que tiene respeto hacia la comunidad como entidad moral, portándose como se espera frente a los demás miembros de la colectividad. Esto le permite acumular respeto y luego volverse uno de estos oradores. Además debe mostrar capacidad para hacer reinar el respeto entre los miembros de la asamblea y hacia la comunidad. Este paso es esencial para llegar a ser un anciano (kuraq). Se hace evidente que el apoyo que se brinda a los kuraq, que son los "jubilados", depende de su carrera social y política así como de la adquisición de estas capacidades. Esto condiciona la posibilidad de "transferir" los derechos de usufructo sobre la tierra. La validación colectiva del comportamiento de cada persona es entonces necesaria para asegurar la posibilidad de transmitir los derechos que uno tenga sobre la tierra ${ }^{22}$.

En lo que respecta a los jóvenes queda la pregunta ¿cómo pueden estos ser aceptados en la comunidad y gozar de la "transferencia"? Para poder recibir tierras, la persona concernida debe haber dado igualmente muestras de respeto hacia la comunidad. Ello adquiere un matiz particular dado que tan solo una parte de los hijos de los pobladores de la comunidad se quedan a vivir en ella. Para estar inscrito como miembro activo, según el reglamento sobre comunidades, uno debe residir en la comunidad y vivir de la agricultura. Esto significa que debió haber participado en las faenas, asistido a asambleas, aceptado algunos cargos menores y haberse comportado con debida consideración ante la asamblea. En otras palabras respetar la jerarquía social, las normas de comportamiento - consentir en no tener voz ni voto al comienzo - así como el conjunto de las decisiones comunales. No obstante, muchos jóvenes en los años 2000 acariciaban la idea de irse de la comunidad. Esta situación se hizo factible años después con las oportunidades de trabajo creadas por el boom minero y las nuevas posibilidades laborales que tienen en otras regiones del país los más jóvenes y con educación (Asencio, 2016). La falta de oportunidades en los años 1990 y 2000 mantuvo a muchos en la comunidad, lo que por otro lado les permitió ejercer cierto control. Sobre todo los jóvenes con estudios mostraron dificultad para aceptar el procedimiento. En la medida que buscaban nuevas oportunidades permanecían muy poco en la comunidad, además de aspirar en asumir el cargo de presiden-

\footnotetext{
22 Como lo es para ascender en la jerarquía social (Hall, 2015).
} 
te sin pasar por las etapas preliminares. No obstante, para inscribirse como comunero activo tenían que mostrar respeto por el procedimiento y el sistema de valores que le daba fundamento, lo que se volvía un requisito necesario para estar en posición de recibir el usufructo de las tierras. Probablemente por el impacto del fenómeno migratorio de los años 1990 y 2000 y debido a las dificultades que podrían encontrar los hijos que partían, los padres preferían esperar antes de proceder a la transferencia de sus tierras. Esto permitía tomar en cuenta las necesidades de los hijos y garantizar a aquellos que fracasaban en su intento por establecerse en la ciudad un fácil retorno a la comunidad. Aunque esta lógica se siga aplicando, encontramos jóvenes que estando fuera de la comunidad mantienen un pie en ella. El sistema de los "comités de residentes [en la ciudad]", se difunde y va cambiando la lógica precedente. La importancia de la colectividad sigue siendo en la comunidad un elemento clave incluso para los que están casi fuera, como demuestra Asencio (2016) en su trabajo sobre los alcaldes rurales de la provincia de Quispicanchi. Esto señala hasta qué punto la colectividad es un referente en la lógica social de este sector de la población.

Podemos decir entonces que la comunidad ejerce un control sobre sus recursos en dos niveles. El primero se produce sobre los que gozan de estos derechos haciendo que cumplan sus obligaciones para con la comunidad. El segundo sobre aquellos que podrían recibir estos derechos para que de igual modo asuman sus obligaciones con ella. En nuestro trabajo de campo pudimos constatar hasta qué punto estos procedimientos ayudan a seleccionar los candidatos de acuerdo a sus antecedentes. Aquella persona que muestra interés, está disponible y acepta diferentes cargos (incluyendo los menos considerados, como el de servir la chicha por ejemplo) tiene mayor preferencia. Como explicó uno de mis informantes en Llanchu, todos se conocen y cuando un joven quiere ingresar a la comunidad, evalúan la persona y sus aptitudes para honrar los valores locales, es decir, el respeto hacia los demás y hacia la comunidad. Este mecanismo hace que la propiedad colectiva de la tierra aparezca como un componente esencial del control social. Más allá, se puede notar que conlleva esto un cierto conservadurismo: al no respetar los valores comunales uno pone en riesgo la posibilidad de mantener, transmitir o recibir el derecho de usufructo de la tierra, y, consiguientemente, las posibilidades de quedarse en la comunidad.

\section{Conclusión}

Al otorgar títulos colectivos de propiedad de la tierra, como el caso de Llanchu, la reforma agraria marcó en el Perú una etapa propicia para las comunidades rurales. Aunque en un primero momento estas se beneficiaron poco de las redistribuciones de tierra, las consecuencias sociológicas y territoriales se hicieron perceptibles en ellas 15 o 20 años después, a medida que las instituciones creadas por la reforma (especialmente cooperativas) colapsaran y parte significativa de sus socios optaran por transformarlas en comunidades campesinas. Esta situación es vigente en la sierra sur donde se encuentra la mayoría de las comunidades campesinas del Perú.

Elementos externos a la comunidad, vía la atribución de títulos de propiedad, impulsaron en Llanchu un proceso de reestructuración social y territorial. Luego de analizar esta dinámica de manera pormenorizada, pudimos llegar a identificar los puntos siguientes. Primero, la comunidad, a pesar de su formación reciente, es la unidad con la cual se identifica la población. Segundo, si el título de propiedad es comu- 
nal, la gestión común de las tierras sigue descansando de manera significativa entre los grupos familiares, variando la importancia del control comunal según las zonas de producción. Tercero, pocas son las parcelas colectivas de la comunidad, estas fueron rápidamente parceladas en zonas de riego quedando bajo dominio comunal tan solo las de secano y pastos. Estos elementos que dejan pensar que la importancia de lo colectivo quedó mermada, muestran más bien que en el caso estudiado no fue necesariamente así. Los instrumentos legales que representan la posesión de un título de propiedad y la formalización del estatus comunal fueron aprovechados por la colectividad — reconocida legalmente como comunidad-, lo que dio lugar a la construcción de lazos sociales en base al territorio legalmente reconocido, en otras palabras, a la formación de una comunidad en el sentido sociológico del término. Se van definiendo incluso los límites sociales, a través de la obtención de tierras, dado que un comunero activo tiene que recibir tierras de riego (informalmente) por transferencia de su familia: la definición de los límites de la comunidad depende así de elementos colectivos y familiares.

La gestión comunal de la tierra y su población descansa pues sobre variadas normas; prevaleciendo así una situación de pluralismo jurídico donde se ha ido negociando una normatividad propia (los "usos y costumbres") dentro del marco normativo y jurídico estatal.

Mediante la reforma y a través de medidas ulteriores, condiciones externas a las comunidades crearon un espacio en el cual el tejido social rural se reestructuró en función del colectivo local. La gestión de la tierra en Llanchu, donde la agricultura familiar predomina aún, sigue siendo el elemento central. En comunidades, donde proyectos agroindustriales o mineros se implantaron, puede ser que la tierra ya no sea el recurso principal administrado (Diez Hurtado, 2012a).

El caso expuesto demuestra cómo una decisión sobre la propiedad de la tierra puede tener impacto en términos sociales. Esto evidencia el hecho de que no se puede racionalizar la gestión de los recursos pensando que simplemente se trata de una cuestión técnica, pues constituye también un asunto político y social. En el contexto actual, marcado por políticas y medidas que hacen frágiles la propiedad colectiva de las tierras, se hace urgente una reflexión sobre la importancia del reconocimiento legal de las tierras comunales. Antes de tomar medidas rápidas y radicales, sería necesario responder primero a las preguntas: ¿cuál es el papel de las comunidades para sus habitantes de hoy en día?, ¿en qué medida la comunidad significa para la población más vulnerable cierta seguridad?, ¿qué sucedería con las comunidades si se privatizaran sus tierras? Lo que está en juego, a nuestro parecer, es el porvenir de este sector de la población en el Perú. Con mayor razón aun tratándose de un país que firmó en 2007 la declaración de las Naciones Unidas sobre los derechos de los pueblos indígenas y en 2011 la ley de consulta previa.

\section{Referencias bibliográficas}

Agrawal, Arun (2003). "Sustainable governance of common-pool resources: Context, Methods, and Politics". Annual Review of Anthropology, 32: 243-262.

Agrawal, Arun; Gibson Clark (2001). Communities and the Environment: Ethnicity, Gender, and the State in Community-based Conservation. New-York, London: Rutgers University Press. 
Asencio, Raúl H (2016). Los nuevos Incas. La economía política del desarrollo rural andino en Quispicanchi (2000-2010). Lima: IEP.

Balandier, Georges (1985). Anthropo-logiques. Paris: Presses Universitaires de France.

Bollier, David (Ed.) (2013). La renaissance des communs. Pour une société de coopération et de partage. Paris: Éditions Charles-Léopold Mayer.

Bollier, David; Silke, Helfrich (Eds.) (2015). Patterns of commoning. Amherst: Mass: Off the Common Books.

Burneo, María Luisa (2013). "Elementos para volver a pensar lo comunal: nuevas formas de acceso a la tierra y presión sobre el recurso en las comunidades campesinas de Colán y Catacaos". Anthropologica del Departamento de Ciencias Sociales, 31: 16-41.

Burneo, Zulema (2013). "Propiedad y tenencia de la tierra en comunidades campesinas. Revisión de literatura reciente en el Perú", en P. Castillo, A. Diez, B. Zulema, J. Urrutia, P. del Valle (Eds.), ¿Qué sabemos de las comunidades campesinas? Lima: ALLPA, Comunidades y desarrollo, 153-258.

Burneo, Zulema ND “La propiedad colectiva de la tierra”. CEPES, 1-11.

Caballero, J. (1977). "Sobre El Carácter De La Reforma Agraria Peruana". Latin American Perspectives, 4: 146-159.

Cadena, Marisol (de la) (2015). Earth Beings: Ecologies of Practice across Andean Worlds. Durham: Duke University Press.

Castillo, Pedro (2013). "Las comunidades campesinas en el siglo XXI : balance jurídico”, en P. Castillo Castañeda, A. Diez Hurtado, B. Zulema, J. Urrutia, P. del Valle. (Eds.), ¿Qué sabemos de las comunidades campesinas? Lima: Grupo Allpa, 15-106.

Castro, Hildebrando (1973). Del ayllu al cooperativismo socialista. Lima: Peisa.

Chamoux, M.N.; Contreras, J. (1996). "Introducción”, en M.N. Chamoux, J. Contreras (Eds.), La gestión comunal de recursos: economía y poder en las sociedades locales de España y de América Latina, Barcelona: Icaria Editorial, 11-47.

Chirinos, Alfonso (1975). "La reforma agraria peruana”. Nueva Sociedad, 21: 47-64.

Degregori, Carlos (2012). "Panorama de la antropología en el Perú", en C. Degregori, P. Sendón, P. Sandoval (Eds.), No hay país más diverso: Compendio de antropología peruana. Lima: Instituto de Estudios Peruanos, 20-73.

Diez, Alejandro (1998). Comunes y haciendas: procesos de comunalización en la Sierra de Piura (siglos XVIII al XX). Piura: CICPA.

- (2011). "Concentración versus colectivización de la propiedad de la tierra en América Latina”, en A. Bartra (Ed.), Memoria del seminario internacional Modelos de desarrollo rural y economía campesina indígena. La Paz, Bolivia: CICPA, 191-198.

Diez, Alejandro (Ed.) (2012a). "Nuevos retos y nuevos recursos para las comunidades campesinas". Tensiones y transformaciones en comunidades campesinas. Lima: PUCP, 21-35.

Diez, Alejandro (2012b). "Gobierno comunal: entre la propiedad y el control territorial. El caso de la comunidad de Catacaos". Perú: el problema agrario en debate. SEPIA, 14: 115-148.

Diez, Alejandro (Ed.) (2012c). Tensiones y transformaciones en comunidades campesinas. Lima: PUCP.

Eguren, Fernando (2013). "Prólogo", en P. Castillo, A. Diez, B. Zulema, J. Urrutia, P. del Valle (Eds.), ¿Que sabemos de las comunidades campesinas? Lima, Peru: Grupo Allpa, 11-14. 
Eguren, Fernando; Del Castillo, Laureano; Burneo, Zulema (2009). "Los derechos de propiedad sobre la tierra en las comunidades campesinas". Economía y sociedad, 71: 28-37.

FIDA - Fondo Internacional de Desarrollo Agrícola. (2013). "Dar a la población rural pobre del Perú la oportunidad de salir de la pobreza". https:/www.ifad.org/ documents/10180/0e194391-56f4-4666-8f50-1eba92ee388d.

Fuenzalida, Fernando (1976). "Estructura de la comunidad de indígenas tradicional - una hipótesis de trabajo", en J. Matos (Ed.), Hacienda, comunidad y campesinado en el Perú. Lima: Instituto de Estudios Peruanos, 219-266.

Garcia, Álvaro (2009). "Indianismo y Marxismo. El desencuentro de dos razones revolucionarias", en La potencia plebeya. Acción colectiva e identidades indígenas, obreras y populares en Bolivia. Bogotá: CLACSO, Siglo del hombre editores, 477-500.

García, Alan (2007). "El síndrome del perro del hortelano". El Commercio, octobre 28. http:// elcomercio.pe/ediciononline/HTML/2008-03-02/el-perro-hortelano-contra-pobre.html.

Glave, Louis; Remy, María (1983). Estructura agraria y vida rural en una región andina: Ollantaytambo entre los siglos XVI-XIX. Cusco, Perú: Centro de Estudios Rurales Andinos 'Bartolomé de las Casas'.

Guillet, David (1979). Agrarian reform and peasant economy in southern Peru. Columbia: University of Missouri Press.

Gutwirth, Serge; Stengers, Isabelle (2016). “Théorie du droit. Le droit à l'épreuve de la résurgence des commons". Revue juridique de l'environnement, 41 (2): 306-343.

Hall, Ingrid (2013). "La reforma agraria, entre memoria y olvido (Andes Sur peruanos)". Antropológica, 31: 101-125.

- (2015). "Compter les journées de travail, classer les individus et ordonner la société dans une communauté des Andes sud-péruviennes". Ethnographiques.org, 29. doi: http:// www.ethnographiques.org/2014/Hall

- (2016). "Parole et hiérarchie dans les Andes du Sud du Pérou". Autrepart, 73 : 89-103.

Kervyn, Bruno (1989). "Campesinos y acción colectiva: La organización del espacio en comunidades de la sierra sur del Perú". La revista andina, 13 (1): 7-60.

Mariátegui, José Carlos; García, Álvaro; Beaudet, Pierre (2012). Indianisme et paysannerie en Amérique latine socialisme et libération nationale. Paris: Syllepse.

Mayer, Enrique (1996). "Propiedad comunal y desarrollo. Conferencia presentada al Congreso de la República del Perú", Octubre 1996. http://www.andes.missouri.edu/ andes/Especiales/EM_Congreso.html.

Murra, John (1985). "El Archipiélago Vertical” Revisited", en Y. Masuda, I. Shimada, C. Morris (Eds.), Andean Ecology and Civilization: An Interdisciplinary Perspective on Andean Ecological Complementarity, Tokyo: University of Tokyo Press, 3-13.

Nobuyuki, Sato (1981). "El concepto de ayllu, y Qata/Q'acun: Un estudio de la familia, el parentesco y el ayllu”, en S. Masuda (Ed.), Estudios etnográficos del Perú meridional, Tokyo: Universidad de Tokio, 139-171.

Ostrom, Eleonor (1990). Governing the Commons: The Evolution of Institutions for Collective Action. Cambridge/New York : Cambridge University Press.

- (2001). "Foreword", en A. Agrawal; C. Gibson (Eds.). Communities and the Environment: Ethnicity, Gender, and the State in Community-based Conservation. New Brunswick, New Jersey, London: Rutgers University Press, ix — xiv.

Ostrom, Eleonor; Hess, Charlotte (2007). "Private and common property rights". Encyclopedia of Law \& Economics. Northampton (MA): Edward Elgar. http://papers.ssrn.com/sol3/ papers.cfm?abstract_id=1304699. 
Pajuelo, Ramón (2012). "Imágenes de la comunidad. Indígenas, campesinos y antropólogos en el Perú", en C. Degregori, P. Sendón, P. Sandoval (Eds.), No hay país más diverso: Compendio de antropología peruana. Instituto de Estudios Peruanos, 123-179.

Pérez, Beatriz (2004). Somos como incas: autoridades tradicionales en los Andes peruanos, Cuzco. Madrid, Frankfurt: Iberoamericana, Vervuert.

Plaza, Orlando; Francke, Marfil (2014 [1991]). "Discusión sobre los orígenes históricos de la comunidad", en J. Urrutia (ed.), Comunidades indígenas y campesinas del Perú: una visión histórica, Lima: Comisión de derechos humanos - COMISEDH, 41-49.

Puente (de la), Juan (2015). "That which belongs to all: Khipus, Community, and Indigenous Legal Activism in the Early Colonial Andes". The americas, 72: 19-54.

Remy, María (2014). "Historia de las comunidades indígenas y campesinas del Perú (entrevista realizada por Javier Torres)", en J. Urrutia (ed.), Comunidades indígenas y campesinas del Perú: una visión histórica, Lima: Comisión de derechos humanos COMISEDH, 109-124.

Robles, Román (2002). Legislación peruana sobre comunidades campesinas. Lima: UNMSM.

Rostworowski, María (1962). "Nuevos datos sobre tenencia de tierras reales en el incario". Revista del Museo Nacional, XXXIXXXI: 130-159.

Roy, Étienne (Le) (2016). "Des Communs 'à double révolution"”. Droit et société, 94: 603-624.

Salomon, Franck (2012). "Etnología en un terreno desigual : encuentros andinos, 1532-1985”, en C. Degregori, P. Sendón, P. Sandoval (eds.), No hay país más diverso: Compendio de antropología peruana II. Lima: PUCP, 18-97.

Seligmann, Linda J. (1995). Between reform \& revolution: political struggles in the Peruvian Andes, 1969-1991. Stanford: Stanford University Press.

Sendón, Pablo F. (2016). Ayllus del Ausangate: parentesco y organización social en los Andes del sur peruano. Lima: PUCP, CBC, IEP.

Schlager, Edella; Ostrom, Elinor (1992). "Property rights regimes and natural resources: A conceptual analysis", Land Economics, 68: 249-262.

SICCAM - Sistema de información sobre comunidades campesinas del Perú. 2016 "Directorio de comunidades campesinas del Perú - 2016". Instituto del bien común / Centro peruanos de estudios sociales. (http://www.ibcperu.org/wp-content/ uploads/2017/06/DIRECTORIO-DE-COMUNIDADES-CAMPESINAS-DELPERU-2016.pdf.)

Trivelli, Carolina (2014). "Reconocimiento legal de comunidades campesinas : una revisión estadística", en Jaime Urrutia (ed.), Comunidades indigenas y campesinas del Perú: una visión histórica. Lima: Comisión de derechos humanos - COMISEDH, 91-108.

Urrutia, Jaime (Ed.) (2014a). Comunidades indígenas y campesinas del Perú: una visión histórica. Lima: Comisión de derechos humanos - COMISEDH.

- (2014b). "Las comunidades campesinas nuevamente en la agenda pública", Comunidades indígenas y campesinas del Perú: una visión histórica. Lima: Comisión de derechos humanos - COMISEDH, 9-20.

Yeckting, Fabiola; Ramírez, Iván (2012). “Antropología, ecología y minería en las comunidades del área andina”. Revista Española de Antropología Americana, 42: 187204. 